\title{
Electronic Banking and Performance of Small and Medium Scale Enterprises in Anambra State, Nigeria
}

\author{
Stella Mbah $^{1} \&$ Jeffery Obiezekwem ${ }^{2}$ \\ ${ }^{1}$ Department of Business Administration, Chukwuemeka Odumegwu Ojukwu University, Anambra State, \\ Nigeria \\ ${ }^{2}$ Department of Entrepreneurship Studies, Chukwuemeka Odumegwu Ojukwu University, Anambra State, \\ Nigeria \\ Correspondence: Stella Mbah, Department of Business Administration, Chukwuemeka Odumegwu Ojukwu \\ University, Anambra State. Nigeria. E-mail: si.mbah@coou.edu.ng
}

Received: March 302019

Accepted: April 25, 2019

Online Published: May 21, 2019

doi:10.5539/ijbm.v14n6p173

URL: https://doi.org/10.5539/ijbm.v14n6p173

\begin{abstract}
This study aims to identify the relationship between electronic banking and performance of small and medium scale enterprises in Anambra state; one of the states with the highest number of SMEs, entrepreneurial skills, informal enterprises and a suitable business environment in Nigeria. To achieve this, the researcher examined performance of SMEs and their association with components of electronic banking; automated teller machine, point of sale services, transaction alerts via short message services (SMS) and mobile banking, through a questionnaire. Three hundred and seventy (73.1\% response rate) copies of questionnaire issued to five hundred and six sampled respondents of 50 SMEs in Anambra state were properly filled and found relevant to the study. The study used SPSS and Excel to identify the descriptive characteristics of the variables of the study and analyze the data. Regression analysis was used to test the hypotheses of the study. Study results concluded that there is positive relationship between; automated teller machine, point of sale services, transaction alerts via short message services (SMS), mobile banking and performance of SMEs in Anambra State, Nigeria. The result also showed that SMEs continuous usage of electronic banking services could be attributed to cost effectiveness, convenience, security, accessibility and diversity of the services. The study recommends among others that, security of electronic banking services should be upgraded by a conjunction between SMEs and banks and that government should provide adequate regulatory framework to protect customers and security of transaction. Furthermore, policy makers in Nigeria should take advantage of the positive revelation of this study to make policies that will increase number of SMEs in Anambra state and Nigeria at large especially from the large number of informal enterprises in Anambra state and Nigeria.
\end{abstract}

Keywords: electronic banking, performance, SMEs, automated teller machine, mobile banking, point of sale service

\section{Introduction}

\subsection{Introduction to the Study}

Across countries at all levels of development, small and medium scale enterprises (SMEs) have an important role to play in achieving the sustainable development goals, by promoting inclusive and sustainable economic growth, providing employment and decent work for all, promoting sustainable industrialization, fostering innovation, creating values and reducing income inequalities (OECD, 2017). For developing nations, sustainable economic growth is real poverty reduction. Thus, the interest in SMEs should be greater in developing countries due to high level of poverty and flexibility of SMEs as compared to other ventures.

In Nigeria, a developing nation with over 160 million people and over $65 \%$ of their populace being below 35 years (SMEDAN/NBS MSME Survey, 2013), it has become imperative for policy makers to seek development of national economy through SMEs rather than rely on the oil sector. This change in Nigeria's economic policy direction is not limited to the depleting state of oil reserve but also because of the abundant potentials; availability of land, cheap labor, etc. of SMEs. Though the change of economic policies in favor of the SMEs has seen a considerable increase in the number of available SMEs, the contribution of this sector to the Gross domestic product (GDP) of Nigeria is low. The Education, wholesale/trade and manufacturing sectors which 
have the highest distribution of SMEs do not account for up to $50 \%$ of independent contribution to the national GDP of Nigeria (SMEDAN/NBS MSME Survey, 2013). This low rate of contribution to the national GDP of Nigeria could be attributed to lack of access to finance, multiple taxation, access to market and obsolete technology that affect the ease of doing business in SMEs (SMEDAN/NBS MSME Survey, 2013). Inability of SMEs to access information communication technology (ICT) is viewed as the major challenge of SMEs to developing strong operations and expand their businesses (Dutta \& Mia, 2009).

Economic sectors that apply advances in ICT are characterized by high level of efficiency, ease and convenience of operation. Inventions of the internet and mobile technology are key information communication technologies that have enhanced the manner of doing business in recent years. The growing number of applicants for internet has also been very crucial in product marketing and distribution in many businesses (Yang, $\mathrm{Li}, \mathrm{Ma}, \&$ Chen, 2018).

Banks are one of the earliest and greatest facilitators of the use of internet technology (Kondabagil, 2007). As leaders of industries in which e-commerce has been developed, they apply internet technology in electronic banking (e-banking) services like online transfer, electronic bill payment and opening of deposit accounts to customers (Sumra, Manzoor, Sumra, \& Abbas, 2011). These services are offered through various initiatives such as phone banking, mobile banking, internet payment systems and internet banking (Kurnia, Peng, \& Liu, 2010). E-banking could improve process excellence, speed of delivery and value of service to customers. Though the success of e-banking services depend on the rate at which the technology is adopted by customers, small and medium scale enterprises inclusive, the question is, how the adoption of e-banking channels by SMEs has influenced their performance.

\subsection{The Study Problem}

Electronic banking is expected to affect the operations and performance of small and medium scale enterprises in a form of transactional convenience, saving of time, quick transaction alert and cost saving (Aliyu, 2012). Despite the acclaimed benefits of electronic banking, the issues of online theft and fraud, non-availability of financial service, payment of hidden cost of electronic banking like Short Message Services (SMS) for sending alert, non-acceptability of Nigerian cards for international transaction, malfunctioning Automated Teller Machines (ATMs) and network downtime has been raised by many users, especially small and medium scale enterprises in Nigeria. In the light of these complaints and to enlarge the body of knowledge on e-banking in Nigeria context, this study aims to prove the relationship between e-banking and SME performance in Anambra State, Nigeria. Anambra state is chosen as the area of study of this research because of its position as one of the states in Nigeria with the largest number of SMEs and people with great entrepreneurial skills, creative and innovative abilities.

This research work is significant to policy makers in making policies that would encourage the growth of the number of SMEs especially from the large number of informal business in Anambra and Nigeria at large. Policies generated from the results of this research would also encourage expansion of existing SMEs to provide raw materials and certain input services to lager enterprises/ventures. These would create more jobs, reduce the poverty rate and increase the GDP of Nigeria.

The elements of the study problem are illustrated by answering the following questions:

1. To what extent is the relationship between automated teller machine services and performance of SMEs significant?

2. To what degree is the relationship between mobile banking services and performance of SMEs significant?

3. How significant is relationship between transaction alerts via SMS and performance of SMEs?

4. How significant is the relationship between point of sale service and performance of SMEs?

\subsection{Objectives of the Study}

The study aims at examining the relationship between electronic banking and performance of small and medium scale enterprises in Anambra State, which is one of the states with the highest number of SMEs in Nigeria.

\subsection{Hypotheses}

The study consists of the following hypotheses:

$\mathrm{Ho}_{1}$ : Automated teller machine services have no significant relationship with performance of SMEs in Anambra State.

$\mathrm{Ho}_{2}$ : Mobile banking services has no significant relationship with performance of SMEs in Anambra State. 
$\mathrm{Ho}_{3}$ : Transaction alerts via SMS have no significant relationship with performance of SMEs in Anambra State.

$\mathrm{Ho}_{4}$ : Point of sale service has no significant relationship with performance of SMEs in Anambra State.

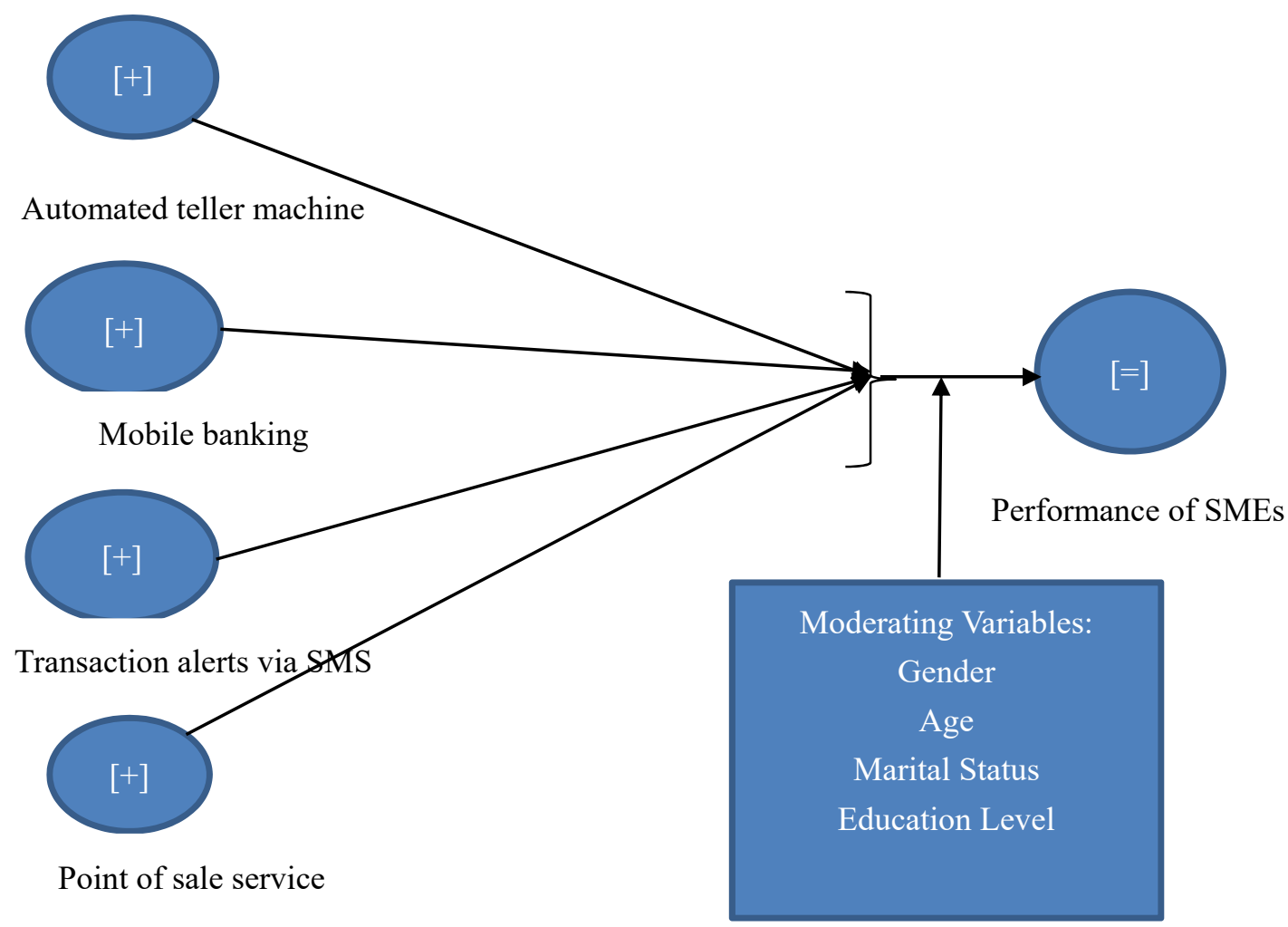

Figure 1. Conceptual framework

\section{Literature Review}

E-banking and performance of SMEs have attracted some empirical attention in literature. For instance, (Nthenya Mutinda, 2014) examined the effect of mobile phone based money transfers on the financial performance of small and medium enterprises in Nairobi County, Kenya. The study adopted descriptive survey method. Data was collected using self-administered questionnaires and interview guide. The collected data was analyzed using Statistical package for Social Sciences software. The results of the study were analyzed using descriptive and inferential statistics and the results were presented using figures and tables. The findings of the study revealed that there is a positive correlation between SMEs financial performance and business growth, efficiency in service delivery, access to information and convenience and reliability. Development of mobile money transfer services influences the development of market; mobile money transfer services enhance efficiency in service delivery in business; access to information in mobile money transfer services depend on the environment and mobile money transfer services are convenient and reliable. The study recommends a comprehensive technology-to-performance model that should include the characteristics of technology, tasks and individuals as explanatory variables for technology use and individual performance.

(Chuwa, 2015) investigated the factors influencing the adoption of internet banking by small and medium enterprises (SMES) in Nyamagana District, Mwanza-Tanzania. Explanations of the methodology used in conducting 425 interviews to obtain primary information for this study is given. Results of the 425 interviews and the analysis of these results; with graphs and figures to determine the extent that the factors studied influenced customer adoption of internet banking, was also analyzed. The research's objectives were tested by using descriptive statistics tools such as bar graphs and statistical tables so as to measure the relationship between consumers' demographic characteristics and the adoption of internet banking. Bar graphs and statistical tables were used to describe differences between users and non-users in terms of their perceptions of internet banking. The key findings revealed that demographic factors including age, income, education level and 
occupation have a relationship with the adoption of internet banking. Psychological factors including perceived relative advantage, perceived compatibility, perceived complexity, perceived risk, and perceived cost were found to influence the adoption of internet banking. Social influences including opinions of friends, parents and colleagues were not found to be significant factors to influence the adoption of internet banking in the Tanzanian context.

(Nahian Riyadh, Shahriar Akter, \& Islam, 2009) investigated the factors that affect SMEs' adoption of e-banking in Bangladesh. Technology Organization-Environment (TOE) framework, Technology Acceptance Model (TAM), Institutional Theory and Institutional Intervention Theory were adopted for the study. With these background theories, an integrated conceptual framework for SMEs' e-banking was developed, which incorporates both the rationalistic goal oriented behavior of firms and the external forces of technology adoption. Seven variables affecting e-banking adoption by SMEs were identified. They are: organizational capabilities, perceived credibility, perceived regulatory support, ICT industries readiness, lack of financial institutions readiness and institutional influence.

In (Monge-Gonzalez, 2011) a randomized controlled experiment was used to determine whether the adoption of internet banking by Banco Nacional de Desarrollo's micro and small enterprise (MSE) clients in Costa Rica has an impact on their performance, measured in terms of productivity, increase in sales, and cost reduction. 41,702 firms were effectively identified and classified to represent the population of Banco Nacional de Desarrollo's micro and small enterprise (MSE). Results from the intervention group surveys indicate that Internet use is limited in MSEs' daily operations because of limited access to computers and the relatively low penetration of Internet services in employees' activities. In addition, firms have limited knowledge about the uses of the Internet as a business development tool. These results contrast with the reported benefits obtained by a small group of firms. Those benefits include reduced costs, higher sales, and better contact with customers.

Thus, this study is based on the reality of e-banking and performance of SMEs, which is a very important sector for the growth of Nigeria's economy. This study highlights the nature of the relationship and the role played by e-banking in the performance of SMEs in one of Nigeria's states, Anambra State, with one of the largest number of SMEs and skilled entrepreneurs and a conducive environment for business and investment. Since the government and policy makers in Nigeria have come to terms with the importance of SMEs in growing the nation's economy, it is important to look at the affinity between technologies like e-banking and performance of SMEs from the various state levels, so as to come up with policies that will benefit SMEs across the country.

\section{Study Methods}

\subsection{Population and Sample}

Survey research design was employed in this study. This study was carried out in Anambra state. Anambra state is chosen as the area of study of this research because of its position as one of the sates in Nigeria with the largest number of SMEs and people with great entrepreneurial skills, creative and innovative abilities. Three major cities (Onitsha, Nnewi, \& Awka) were studied. The target population of the study consisted of 50 SMEs in Anambra State. A sample size of 506 was mathematically determined from 2621 population of management and employees in the 50 SMEs using Borg and Gall (1973) formula. Simple random sampling technique was employed to select the management and employees of the SMEs for the study. The reason for using simple random sampling technique was to give every individual equal opportunity of being selected for the study.

The study used copies of structured questionnaire to elicit information from the sampled respondents. The copies of questionnaire contained questions that utilize the 5 point Likert rating scale (Strongly agree, agree, undecided, strongly disagreed and disagreed).

A total of five hundred and six copies (506) of questionnaires were distributed to the respondents, out of which three hundred and seventy ( $73.1 \%$ response rate) were properly filled and found relevant to the study. Descriptive statistics, correlation analysis and multiple regression analysis was employed in analyzing the data. 
Table 1. Characteristics of study sample

\begin{tabular}{lll}
\hline & Frequency & Percentage \\
\hline GENDER & & \\
Male & 271 & 73.2 \\
Female & 99 & 26.8 \\
Total & 370 & 100.0 \\
AGE & & \\
$20-30$ years & 44 & 11.9 \\
31-40 years & 114 & 30.8 \\
41-50 years & 150 & 40.5 \\
51years and above & 62 & 16.8 \\
Total & 370 & 100.0 \\
MARITAL STATUS & & \\
Marital status & 64 & 17.3 \\
Married & 290 & 78.4 \\
Separated/divorced & 16 & 4.3 \\
Total & 370 & 100.0 \\
EDUCATIONAL & & \\
QUALIFICATION & & \\
OND/NCE/O'LEVEL & 159 & 43.0 \\
B.Sc./HND & 144 & 38.9 \\
M.Sc./MBA & 67 & 18.1 \\
Total & 370 & 100.0 \\
\hline
\end{tabular}

\subsection{Sources of Data Collection}

Data for the survey conducted was sourced from primary sources. Primary data was obtained from the study sample of selected SMEs in Anambra State through the use of questionnaire

\subsection{Measure of Variables of Study}

The study variables consist of one dependent variable and four independent variables:

(1) Independent variables:

The independent variables are components of electronic banking, which include: transaction alerts via SMS (TASMS), automated teller machine (ATM), Mobile Banking (MB) and Point of Sale (POS).

(2) Dependent variable: the performance of SMEs (PSMEs)

Relationship between electronic banking and performance of performance SMES was evaluated using multiple regression analysis. The regression model used is represented as;

$$
\mathrm{Y}=\alpha+\beta_{1} \mathrm{X}_{1}+\beta_{2} \mathrm{X}_{2}+\beta_{3} \mathrm{X}_{3}+\beta_{\mathrm{n}} \mathrm{X}_{\mathrm{n}}+\mathrm{e}
$$

Where:

$\mathrm{Y}=$ Performance of SMEs (PSMEs)

$\alpha=$ Constant Term

$\beta=$ Beta coefficients

$\mathrm{X}_{1}=$ Transaction Alerts Via SMS (TASMS)

$\mathrm{X}_{2}=$ Automated Teller Machine (ATM)

$\mathrm{X}_{3}=$ Mobile Banking (MB)

$\mathrm{X}_{4}=$ Point of Sale (POS)

$\mathrm{e}=$ Error Term

\subsection{Statistical Methods}

The researchers used the SPSS program to analyze the study data collected from the questionnaire to test hypotheses and achieve the objectives of the study. It gave means, standard deviations and correlations of each 
independent and dependent variable. The statistical methods include frequencies, the mean, standard deviations and simple regression.

\subsection{Reliability of the Instrument}

Cronbach-Alpha test was used to verify the stability and internal consistency in the questions in the questionnaire. The result of the alpha coefficient value was 0.951 , which shows that there is high degree of consistency for all questions.

\section{The Results}

SPSS and EXCEL were used to analyze the study data and to identify the descriptive characteristics of the dependent and independent study variables and the results of the hypothesis test. Table (2) presents the descriptive statistics of the variables of the study. Each hypothesis and descriptive statistics of their variables are shown in table 2 and table 3 :

\subsection{Statistics of the Variables of the Study}

Table 2. Descriptive statistics of the variables of the study

\begin{tabular}{llllll}
\hline & N & Min & Max & Mean & Std. dev. \\
\hline ATM & 370 & 13 & 25 & 18.39 & 2.972 \\
MB & 370 & 13 & 25 & 18.98 & 3.085 \\
TASMS & 370 & 13 & 25 & 18.07 & 2.516 \\
POS & 370 & 13 & 24 & 17.71 & 2.536 \\
PSMES & 370 & 13 & 25 & 20.13 & 3.184 \\
Valid N & 370 & & & & \\
\hline
\end{tabular}

\subsection{Hypotheses Testing and Result Discussion}

Table 3. Regression analysis of study hypotheses

\begin{tabular}{lllll}
\hline Hypotheses & T & T.Sig. & Result of Ho & Result of H1 \\
\hline HO1 & 4.848 & .000 & rejected & accepted \\
HO2 & 3.089 & .000 & rejected & accepted \\
HO3 & 2.387 & .007 & rejected & accepted \\
HO4 & 2.131 & .000 & rejected & accepted \\
& & & \\
\hline
\end{tabular}

HO1: Automated teller machine services have no significant relationship with performance of SMEs in Anambra State.

The performance of SMEs (PSMEs) was measured using MRA method, where the relationship between ATM and PSMEs was measured by questions 1 to 5 in the questionnaire.

Table 3 shows the result of the relationship between ATMS and PSMES, where the value of P-value sig. $=0.000$, which is less than the significant level $\mathrm{a}=0.05$, thus rejecting the null hypotheses and accepting the alternative hypothesis, that is, Automated teller machine services have a significant relationship with performance of SMEs in Anambra State.

HO2: Mobile banking services have no significant relationship with performance of SMEs in Anambra State.

The performance of SMEs was measured using MRA method, where the relationship between MB and PSMEs was measured by questions 6 to 10 in the questionnaire.

Table 3 shows the result of the relationship between MB and PSMEs, where the value of P-value sig. $=0.007$, which is less than the significant level $\mathrm{a}=0.05$, thus rejecting the null hypothesis and accepting the alternative hypothesis, that is, Mobile banking services has a significant relationship with performance of SMEs in Anambra State.

HO3: Transaction alerts via SMS have no significant relationship with performance of SMEs in Anambra State. The performance of SMEs was measured using MRA method, where the relationship between TASMS and PSMEs was measured by questions 11 to 15 in the questionnaire. 
Table 3 shows the result of the relationship between TASMS and PSMEs, where the value of P-value sig. = 0.000 , which is less than the significant level $\mathrm{a}=0.05$, thus rejecting the null hypothesis and accepting the alternative hypothesis, that is, Transaction alerts via SMS have a significant relationship with performance of SMEs in Anambra State.

HO4: Point of sale service has no significant relationship with performance of SMEs in Anambra State.

The performance of SMESs was measured using MRA method, where the relationship between POS and PSMEs was measured by questions 16 to 20 in the questionnaire.

Table 3 shows the result of the relationship between POS and PSMEs, where the value of P-value sig. $=0.000$, which is less than the significant level $\mathrm{a}=0.05$, thus rejecting the null hypothesis and accepting the alternative hypothesis, that is, Point of sale service has a significant relationship with performance of SMEs in Anambra State.

\section{Conclusions and Recommendations}

\subsection{Conclusions}

This work examined the relationship between electronic banking and performance of SMEs in Anambra State. Data were sourced from management and employees of 50 SMEs in Anambra State. The study found that, transaction alerts via SMS, automated teller machine services, mobile banking services and point of sale services have significant positive relationship with the performance of SMEs in Anambra State. It reveals that ease of use, cost effectiveness, convenience, security of the service, accessibility and diversity have enabled SMEs to continue to use e-banking services. Based on the aforementioned findings, the study concludes that electronic banking has significant positive relationship with the performance of SMEs in Nigeria.

\subsection{Recommendations}

Finally, the following recommendations were proposed:

The positive results reached are supposed to support, promote and increase attention to the Variables of electronic banking and performance of SMEs. It is therefore important that SMEs in conjunction with banks constantly improve and upgrade their e-banking system's security in order to reduce the security threat to the system. Government should provide adequate regulatory framework that will ensure customer protection, and security of transaction. That way, SMEs' confidence in electronic banking would be secured.

Mobile banking service providers should enhance the service by developing more friendly, easy to use and efficient applications for SMEs in Anambra State.

Small and medium scale enterprises should work hand in hand with banks in order to provide ATM terminals and POS services in their vicinity to ensure easy accessibility.

The need to research and expand the society of the study to include other states in subsequent studies, especially those states with few number of registered SMES in Nigeria and beyond Nigeria. This could be useful in ascertaining the reason why these states have few numbers of SMEs.

\section{References}

Aliyu, A. (2012). The Impact of Electronic Banking on customer service delivery in the Malaysian Banking industry: Using Sand Cone Model. TIJ's Research Journal of Science \& IT Management - RJSITM, 1(11), 11-22. $\quad$ Retrieved from http://www.theinternationaljournal.org/ojs/index.php?journal=rjitsm\&page=article\&op=view\&path $\% 5 B \%$ $5 \mathrm{D}=1235$

Chuwa, G. (2015). Factors Influencing the Adoption of Internet Banking by Small and Medium Enterprises (SMEs) in Nyamagana District, Mwanza-Tanzania. European Journal of Business and Management, 7(13), 135-159. Retrieved from https://www.iiste.org/Journals/index.php/EJBM/article/view/22129

Dutta, S., \& Mia, I. (2009). The Global Information Technology Report 2008-2009. Mobility in a Networked World. Retrieved

from http://evconsulting.com/sites/default/files/attachments/pdf/WEF_GITR_Report_2008-09.pdf

Kondabagil, J. (2007). Risk management in electronic banking: concepts and best practices. Retrieved from https://www.wiley.com/en-ao/Risk+Management+in+Electronic+Banking\%3A+Concepts+and+Best+Pract ices-p-9781118390436

Kurnia, S., Peng, F., \& Liu, Y. R. (2010). Understanding the Adoption of Electronic Banking in China. 2010 43rd 
Hawaii International Conference on System Sciences, 1-10. https://doi.org/10.1109/HICSS.2010.421

Monge-Gonzalez, R. (2011). The Impact of Internet Banking on the Performance of Micro and Small Enterprises in Costa Rica: A Randomized Controlled Experiment. Retrieved from Washington, DC: Inter-American Development Bank (IDB) website: https://www.econstor.eu/handle/10419/88971

Nahian Riyadh, A., Shahriar Akter, M., \& Islam, N. (2009). The Adoption of E-banking in Developing Countries: A Theoretical Model for SMEs. In International Review of Business Research Papers (Vol. 5). Retrieved from

https://s3.amazonaws.com/academia.edu.documents/30844536/17.-Riyadh.pdf?AWSAccessKeyId=AKIAI WOWYYGZ2Y53UL3A\&Expires=1553876240\&Signature=9aqdR95rCCyFFBQ25Oyuld\%2BCFFY\%3

D\&response-content-disposition=inline\%3B filename\%3DThe_adoption_of_e-banking_in_developing.pdf

Nthenya Mutinda, A. (2014). The Effect of Mobile Phone Based Money Transfers on the Financial Performance of Small and Medium Entreprises in Nairobi County, Kenya (University of Nairobi, Kenya). Retrieved from https://pdfs.semanticscholar.org/e00c/500e0411c82455573f3bceb0dbc9f060c26c.pdf

OECD. (2017). Ehancing the Contributions of SMEs in a Global and Digitalised Economy. Retrieved from https://www.oecd.org/mcm/documents/C-MIN-2017-8-EN.pdf

SMEDAN/NBS MSME Survey. (2013). Smedan and NAtional Bureau of Statistics Collaborative Survey: Selected Findings (2013). $\quad$ Retrieved from https://www.smedan.gov.ng/images/PDF/2013-MSME-Survey-Summary-Report.pdf

Sumra, S. H., Manzoor, M. K., Sumra, H. H., \& Abbas, M. (2011). The Impact of E-Banking on the Profitability of Banks: A Study of Pakistani Banks. Journal of Public Administration and Governance, 1(1). https://doi.org/10.5296/jpag.v1i1.692

Yang, S., Li, Z., Ma, Y., \& Chen, X. (2018). Does Electronic Banking Really Improve Bank Performance? Evidence in China. International Journal of Economics and Finance, 10(2), 82. https://doi.org/10.5539/ijef.v10n2p82

\section{Copyrights}

Copyright for this article is retained by the author(s), with first publication rights granted to the journal.

This is an open-access article distributed under the terms and conditions of the Creative Commons Attribution license (http://creativecommons.org/licenses/by/4.0/). 